\title{
POST-MENISCECTOMY REHABILITATION
}

\author{
ELLIS JANKS, B.Sc. (Physio) (Witwatersrand), B.Sc. (Med.) (Hons.), Sports Science (U.C.T.)*
}

\section{SUMMARY}

Removal of the semi-lunar carilage/s (menisci) of the knee is a common surgical procedure. Surgeons recognize the importance of an exercise programme supervised by a physiotherapist, in order to obtain the best post-operative rehabilitation. However, the best method of post-operative rehabilitation has been a controversial issue. Controlled studies to determine the relative effectiveness of different trealment regimes are reviewed. Substantial research is being carried out to determine the physiological effects of surgical procedures, subsequent immobilization and different forms of exercise on the leg. These are discussed and considered in formulating the ideal post-meniscectomy rehabilitation programme. The effects and importance of isokinetic exercise is emphasized.

\section{INTRODUCTION}

The aim of a rehabilitation programme is to ret urn the patient to full functional capacity in as short a time as possible. Clearly, functional demands differ from patient to patient and this must be considered when a rehabilitation programme is formulated. The physiological changes which occur after meniscectomy and the subsequent immobilization of the injured leg are reviewed. The physiological effects of the various types of exercise are considered and these a re applied in the formulation of a postmeniscectomy rehabilitation programme.

\section{PRE-OPERATIVE MANAGEMENT}

For patients with chronic injuries, a pre-operative programme of exercises should be performed. Logic suggests that this should strengthen the leg prior to surgery (McAustland, 1943; Luck et al., 1948; Wyn-Parry et al., 1958), and should introduce the patient to the type of exercise he will be required to perform immediately after the operation (Meekison, I944; Yocum el al. 1978). It should be noted, however, that no controlled studies have been performed to determine whether or not pre-surgical conditioning is of any value.

\section{POST-OPERATIVE CARE}

Immediately (first hours) after surgery

Exercise rehabilitation should start soon after the operation, possibly even in the anaesthetic recovery room. Logically, this should help to minimise muscle atrophy and weakness which results from partial or total post-operative immobilization of the leg (McAustland. 1943; Luck et al., 1948; Meekison. I944; Wynn-Parry et al., 1958). This has not yet been proven. Tourniquet-induced ischaemic damage to nerves and muscle may prevent effectivc voluntary movement immediately after surgery (Weingarden et al., 1979). This part of the exercise programme may therefore be of limited value and is a possible area for further investigation.

*Private Practitioner, Cape Town.

Received 10 January $[983$.

\section{OPSOMMING}

Verwydering van die semi-lunêre kraakbeen (menisci) van die knie is 'n algemene chirurgiese prosedure. Chirurge erken die belang van 'n oefenprogram onder toesig van 'n fisioterapeul vir die beste post-operatiewe rehabilitasie. Dog. die beste melode van post-operatiewe rehabilitasie bly betwisbaar. Gekontrolecrde studies om die relatiene effekriwiteit van verskillende behandelingsprogramme te bepaal, word beskryf. Heehtat navorsing word rans gedoen om die fisiologiese effekle van chirurgie, immobilisasie en verskillende vorms van oefening op die been to bepaal. Dit word bespreek en oorweeg in die formulering van die ideale post-menisek tomie rehabilitasie program. Die effekte en belang van isokinetiese oefening word beklemioon.

\section{Subsequent days after surgery.}

There have been two traditional methods of early management of patients who have had meniscectomies. In the first treatment regime (I) a compression bandage of the Robert Jones type is applied from mid-thigh to below the knee soon after the opcration, and the patient is confined to bed for about ten days, after which his stitches a re removed. The patient exercises by first performing static contractions of the quadriceps femoris muscles and later. straight leg raises are added. Knee flexion is attempted when it is performed within the limits of pain experienced by the patient. The patient is allowed to walk. first taking partial weight on the injured leg with the aid of crutches, and progressing to full weight bearing by about two to three weeks.

In the second trcatment regime (II), an ankle to groin plaster cast is applied to the leg over a comprcssion bandage. The cast is either applied immediately after the operation or shortly thereafter. The patient is allowed out of bed and walking with the aid of crutches within days of the operation. He may bear full weight on the operated leg as soon as pain permits.

A number of controlled studies have been performed to determine the relative effectiveness of the two different treatment regimes (Nelson, 1968; Rosborough. 1979; Gough, 1975; Leonard, 1975). Others have reported results obtained when using one or other of the regimes (Smillie, I963; Dutchie and McLoed, 1943; Wynn-Parry et al., 1958; Terhurne et al., 1943; Lantzounis, 1931). The results of these are summarized in Table I.

The results in this table suggest that patients treated with regime II appear to have fewer days off work and fewer postoperative complications than do patients treated with regime I, although in some studies the differences are not marked.

The results of these studies are based purely on subjective observations. The degree of function that the patient has before returning to work may vary greatly between individuals. Their motivation to return to work may likewise be different. Pain perception and post-operative complications may also be viewed as being largely subjective. Therefore, the results are not completely valid parameters on which to base a scientific comparison of the respective treatment regimes. A more effective method of evaluating the return of muscle strength after surgery would be to 
Table 1.

\begin{tabular}{|c|c|c|c|c|c|c|}
\hline \multirow[t]{2}{*}{ Author } & \multirow[t]{2}{*}{ Type of patient } & \multicolumn{2}{|c|}{$\begin{array}{l}\text { Regime } \\
\text { followed }\end{array}$} & \multirow[t]{2}{*}{$\begin{array}{l}\text { days off } \\
\text { work }\end{array}$} & \multicolumn{2}{|c|}{$\begin{array}{l}\text { Post-operative } \\
\text { complications }\end{array}$} \\
\hline & & I & II & & I & II \\
\hline $\begin{array}{l}\text { Smillie (1963) } \\
\text { Dutchie \& Mcloed }\end{array}$ & Service \& heavy & $\mathrm{X}$ & - & 90 & - & - \\
\hline $\begin{array}{l}\text { (1943) } \\
\text { Wynn-Parry et al. }\end{array}$ & Army & $\mathrm{X}$ & - & 82 & - & - \\
\hline (1958) & Air Force & $X$ & - & 62 & - & - \\
\hline Terhune et al. (1943) & All occupations & - & $\mathrm{X}$ & 50 & - & - \\
\hline Lantzounis (1931) & All occupations & & & 38 & - & - \\
\hline Nelson (1968) & All occupations & $\mathrm{X}$ & & 43.5 & - & - \\
\hline Gough (1975) & All occupations & $\mathrm{X}$ & $\mathrm{X}$ & $\begin{array}{l}42 \\
52\end{array}$ & - & - \\
\hline Leonard (1975) & All occupations & $\mathrm{X}$ & $\mathrm{X}$ & $\begin{array}{l}45 \\
53.5 \\
51\end{array}$ & $\overline{23,4} \%$ & $\overline{15,2 \%}$ \\
\hline Rosborough (1970) & Not stated & $X$ & $\mathrm{X}$ & $\begin{array}{l}51 \\
\text { II was } \\
\text { less than } \\
\text { I - value } \\
\text { not given }\end{array}$ & $23 \%$ & $10 \%$ \\
\hline
\end{tabular}

measure the strength of the leg muscles during isokinetic contraction throughout the full range of knee movement at different contraction velocities.

The more vigorous approach of putting the operated leg in a plaster cast (regime II) seems to yield slightly better treatment results than the more conservative treatment (Regime I). Additional advantages of placing the operated leg in a plaster cast immediately after surgery are:

- Protection of the operation site from damage due to movement of the knee/leg.

- When considering the limited availability of space and staff in hospitals and the high costs of keeping a patient in hospital, it makes good sense to discharge the patient in the quickest possible time (Gough, 1975). This is best achieved by placing the operated leg in a long leg plaster cast and getting the patient up and walking as soon as possible.

\section{Possible disadvantages a re:}

- Joint and muscle changes. Although there are definite changes in a joint and its surrounding structures when the joint is immobilized, all soft tissue changes in rabbit limbs are reversible if the limb is not immobilized for more than thirty days (McDonough. 1981). Similarly, in spite of the long leg plaster being ca refully applied, there will still be a certain amount of movement of the leg within the plaster cast (Krackow and Vetter, 1981). The refore, to put a leg into a long leg plaster cast (ank le to groin) for 10 to 14 days should not cause any lasting or irreversible changes to the knee joint or leg muscles (Eriksson. 1981).

\section{SUBSEQUENT POST-OPERATIVE TREATMENT}

Until recently, exercise rehabilitation programmes for this stage of treatment have emphasized strength training for the injured leg to the exclusion of all else. It is now apparent that equal, if not more attention must be given to

- the speed at which the exercises are performed, and

- the endurance training of the muscles. (Campbell and Glenn, 1979).

Thus, although knee function may appear to be "normal" in that after a strength-training programme the patient is

able to lift the same weight with operated and non-operated legs, the operated leg may in fact not yet be "normal" in other respects. It may, for example, be weak at higher or lower contraction velocities and it may have reduced endurance capacity. Either or both of these deficiencies are likely to increase the chances of re-injury.

The principles of treatment are:

- A pre-operative strengthening programme of exercises should be given.

- Exercise of the injured leg is started as soon after the operation as possible.

- The leg is placed in a plaster cast until the stitches are removed. The patient can bear full weight on the operated leg when pain permits.

- Knee flexion exercises are commenced as soon as the plaster cast is removed.

- Exercise training must emphasize the development of both muscle strength and endurance.

\section{THE NATURE OF THE DECREASED MUSCLE STRENGTH AFTER LIMB IMMOBILIZATION}

There is good evidence that muscle strength is decreased after surgery (Eriksson, 1981; Yocum et al., 1978). There are three possible reasons for this:

\section{Muscle fibre atrophy}

Muscle fibre atrophy becomes apparent shortly after the onset of limb immobilization, having been found immediately (Campbell and Glenn, 1979) or within the first week (Eriksson, 1981) after surgery.

\section{Change in fibre composition of the muscle}

Eriksson (1981) showed that there was a considerable decrease in Type 1 (slow twitch) leg muscle fibres after immobilization. Following a few months of intensive exercisc rehabilitation the original proportion of muscle fibre types was achieved. It was also shown that immobilization of the leg in a position in which the muscle was under tension, caused less Type 1 muscle fibre at rophy than occurred when the muscle was immobilized in the relaxed position. 


\section{Neurological factors}

Neurological factors play an important role in the increase in muscle strength after cxercise rehabilitation and may be more important than hypertrophy of the muscle. The evidence for this has been supplied by Grimby (1982) who reported that when subjects are trained at low isokinet ic (see following section) contraction velocities $\left(60^{\circ} / \mathrm{sec}\right)$, increases in their peak torque production can be achicved without either changes in limb eross-sectional girth or muscle fibre area. But, after being trained at last contraction velocities $\left(300^{\circ} / \mathrm{sec}\right)$, the increased torques produced were associated with enlargement of Type II fibres.

This suggests that increased peak torque values achieved after training at high contraction velocitics are due to hypertrophy of Type II muscle fibres. while at lower contractile velocities, neurological adaptations may be operative (Covle el al. 1981). These adaptations could include: the type of motor unit being recruited. the number of motor units being recruited and the frequency of motor unit activation (Sherman $e l$ al., 1982). A more efficient summation of motor units would also causc the muscle to produce increased torque (Covle el al., 1981). Any or all these adaptations could explain the "cross-over effect" in which the strength of the contra-lateral, non-operated leg is increased after isokinctic training (see later). This form of strength increase also occurs in the absence of an increase in muscle size.

When a muscle contracts through its full rangc. it produces different torques at different muscle lengths of joint angles. The torque produced by a muscle in vivo is determined by two factors:

- the amount of overlap of the actin and myosin filaments

(i.c. the sarcomere length) in accordance with the elassic length-tension curve of muscle contraction (Fox and Mathews. 1981: Gowitzke and Milner, 1980).

- The change in mechanical advantage experienced by a muscle as the joint (and therefore limb) moves through its range of movement. In vivo, the muscles produce their peak torques at the joint angle that produces the optimal mechanical advantage.

During knee extension, maximal torque is produced at $56^{\circ}$ knec flexion and this is truc for all angular velocities of knec movement. Thus it is reasonable to conclude that weight lifting as the sole method of exercise rchabilitation is not acceptable, as the muscles will be working maximally during only those parts of its range of movement, at which the joint has low mechanical advantage. To overcome this limitation, isokinctic exercise is suggested.

\section{THE CONCEPT OF ISOKINETIC TRAINING}

\section{What is isokinetic exercise?}

During isokinetic exercisc, movement is performed at a constant angular velocity. This type of exercise allows the resistance against which the muscle contracts to accommodate to the muscular force that is developed throughout the entire range of joint motion. It is therelore possible for the patient to maintain maximum force of muscle contraction throughout the full range of joint/muscle motion (Grimby, 1982; Sherman et al., 1982). Thus, maximum strength training takes place through the entire range of joint/muscle motion.

\section{The importance of contraction speed in muscle rehabilitation}

The peak tension that a muscle is able to develop changes with the speed of muscle contraction, there being a fall in the peak torque produced as the speed of the contraction increases. (Coyle el al. 1979: Fox and Mathews. 1981: Westers, 1982: Sherman ef al. 1982). Thus there is a $40 \%$ fall in the torcue produced as the angular velocity is increased from 30 to 180 per second (Grimby, 1982). The fall in the maxim um torque has a similar pattern in men and women of all ages.

However, it has been shown that muscles with a high percentage of Type II (fast twitch) fibres show less reduction in the maximum torque developed at increasing contraction velocities, than do muscles with a lower percentage of Type II fibres (McArdle el al., 1981: Fox and Mathews. 1981; Grimby, 1982). This indicates the importance of Type II fibres in the development of force at higher contraction speeds. When exercise is performed at low contraction velocities $(30 \%$ of maximum voluntary contraction (M.V.C.)). glycogen depletion is found mainly in Type I (slow twitch) muscle fibres. while at $50 \%$ M.V.C. the depletion is mainly in Type Il fibres (Grimby. 1982).

Thus it may be deduced that training a muscle at different angular velocities during a rehabilitation programme will affect diflerent muscle fibre types. so that the training velocity must be specific to the velocity achic ved during the particular activity or sport in which the subject participates. Most functional activities employ muscle contraction speeds in excess of 240 degrees per second $(\% \mathrm{sec}$.) (Smith and Melton. 1981). For example. during the last $12^{\circ}$ of the swing phase of the gait cycle, the quadriceps muscles cont ract and extend the knee at $233^{\circ} / \mathrm{sec}$. (Wyatt and Edwards, 1981). Thus, high contraction velocitics should be used in the rehabilitation programme before the person attempts functional activities.

A second reason for the use of last contraction speeds during rehabilitation is that at high contraction speeds the compression force at the joint is less than at lower contraction speeds. This is due to the lower force that the muscles can produce at the high contraction velocities (Grimby. 1982). After meniscectomy. it would be of benefir to limit the compression forces acting on the knee joint as these may damage the articular cartilage. Thus, high contraction velocities should be used in the carly stages of the rehabilitation programme (sce isokinetic programme progression).

\section{The effects of training at different contractile velocities}

Costill ef al. (1979) reported that muscles trained at an angular velocity of $180^{\circ} / \mathrm{sec}$. produced increased peak torques when contracting at $180^{\circ} / \mathrm{sec}$. or at slower speeds, but not at higher angular velocities. Similar findings have been made by Covle $c$ al., (1981) who used contraction velocities of 60 and $300 \% \mathrm{sec}$. The group trained at $60^{\circ} / \mathrm{sec}$. showed improvements in peak torque at $60 \% \mathrm{sec}$. and at $0^{\circ} / \mathrm{sec}$. (isometric contractions). while the group trained at $300^{\circ} / \mathrm{sec}$. improved muscle peak torques at $0^{\circ}$. $60^{\circ}$ and $300^{\circ} / \mathrm{sec}$. However, the greatest increase in the peak torque occurred at the specific angular velocity at which the muscles were trained. Similarly. Sherman et al. (1982) trained athletes. Who had undergone meniscectomies, at high velocities. However. when the strength of the operated leg had fully recovered at high contraction velocities, there were still strength deficits of up to $20 \%$ during lower speed isokinetic contractions. Thus, the leg must be treated at slow and fast contraction velocities to ensure that it has regained its full strength.

\section{THE EFFECTS OF ENDURANCE TRAINING}

Re-injury of a limb may result from the premature 
fatiguing of muscles that have had insufficient endurance training after surgerv. Costill et al. (1977) compared a group of patients who had undergone meniscectomies and did progressive strength training. with a similar group who supplemented their strength training programme with 20 to 30 minutes' one-legged cycling daily, with the operated leg. They found that succinate dehydrogenase (S.D.H .) activity in the operated leg. which had decreased after the leg had been immobilized in a plaster cast. had not returned to control levels when only strength training was performed. However. the patients that performed both strength and endurance training. had higher S.D.H. activity in the operated leg muscles than in the non-operated legs.

In summary, the studies reviewed above indicate that exercise training of a limb must involve a complete rehabilitation programme which includes:

- isokinetic training at a full range of muscle contraction velocities. Only in this way will all muscle fïbres (Tvpe I and Type II fibres) be strengthened.

- endurance training.

Unless the muscles have regained their full strength and endurance, the patient is not ready to resume his normal sporting or daily activities due to risk of re-injury.

\section{THE REHABILITATION PROGRAMME}

The following is an example of an ideal rehabilitation programme for a patient who has undergone a meniscectomy. It takes into account the aspects of muscle physiology which have been outlined. The programme requires the use of isokinetic exercising apparatus. In addition. the patient will require a substantial amount of supervision in order to carry out the entire rehabilitation programme. The physiotherapist will not always be in a position to provide a complete programme due to the unavailability of some apparatus and/or supervision time. Therefore, improvisation must be made where necessary.

\section{Pre-operative programme}

\section{Ains}

- To strengthen the muscles around the knee.

- To familiarize the patient with the post-operative exercises.

\section{Exercises}

- Static/isomet ric quadriceps contractions. These are best done with the foot in dorsiflexion (Gough and Ladley, 1971).

- Straight leg raising (S.L.R.) in supine, i.e. hip flexion.

- S.L.R. in prone, i.e. hip extension.

- S.L.R in side-lying, i.e. hip abduction.

- Resisted knee flexion and extension. performed in prone and using the unaffected leg to resist the injured leg.

- Knee flexion and extension, using isokinet ic apparatus (only in cases where the injury is chronic).

\section{Proviso}

Exercises ma y cause excessive pain and/or further damage to the patient's knee.

\section{Post-operative programme}

\section{Stage I}

Immediately post-operative until the removal of the plaster cast.

\section{In the anaesthetic recovery room}

Aims

- To maintain muscle strength.
- To prevent muscle atrophy.

- To aid haemodvnamic function.

\section{Evercises}

- Static/isomet ric quadriccps contractions

- Active ankle and foot movements.

- Attempted S.L.R. in supine.

\section{Proviso}

It may not be possible to perform these exercises due to neural damage during the operation. e.g. tourniquet-induced ischaemia.

In the liard

Aims

- To maintain/increase muscle strength.

- To prevent muscle atrophy.

Principles

- The exercises are performed hourly, initially under supervision and later without supervision.

- Each exercise is performed until the muscles fatigue.

- The patient may start to walk, with the aid of crutches. as soon as he wishes. The physiotherapist must ensure that the patient is able to maintain his balance before allowing him to walk without supervision. The patient mav toetouch at first and progressively take more weight on the operated leg until he bears full weight on it.

- The patient should exercise the rest of his body in order to maintain genera! fitness.

\section{Evercises}

- Isometric quadriceps contractions. If there is evidence of strain on the operation site. quadriceps contractions and S.L.R.'s can be attempted with the hip held in slight internal rotation (Yocum el al., 1979).

- Attempted S.L.R. in supine.

- Attempted S.L.R. in prone.

- Attempted S. L.R. in side-lying.

\section{Stage II}

The period afrer the plaster cast is removed Aims

- To strengthen the leg muscles fully.

- To train the leg muscle endurance.

- To achicve full range knce movement

\section{Principles}

- The exercises are performed 3 - 7 times per week in a suitably cquipped gymnasium.

- The patient may at first walk with crutches, progressing to unaided gait when strength, pain and confidence allows.

- S.L.R. is performed with light weights (e.g. $1 \mathrm{~kg}$ ) placed on the foot. Progression is made by increasing the mass of weights lifted. When $10 \mathrm{kgcan}$ be lifted 10 times without a rest, isokinetic training may be started (Sherman el al., 1981).

- Knee flexion exercises are started immediately after the cast is removed

- If the knee joint becomes painful or oedematous, treat by appropriate physiotherapeutic techniques.

- Isokinetic exercise procedure: (based on the procedure described by Sherman et al., 1981).

- Begin knec flexion and extension exercises at $60^{\circ} / \mathrm{sec}$. and progress to $120,180,240$ and $300^{\circ} / \mathrm{sec}$.

- Higher angular velocity exercises are performed as soon as a torque can be developed at that higher speed (i.e. weak muscles cannot develop torque 
when contracting at high velocities). This will help to minimise possible joint damage caused by the high joint compression forces associated with high tension, low velocity muscle action.

- Exercising at a particular angular velocity is stopped when the torque generated is $50 \%$ of the initial torque during that particular set.

- Two sets of exercise until fatigue are performed at each training velocity with a $3-5$ minute rest between sets.

- Cycling exercises may be started when the knee has about $20^{\circ}$ flexion. At first, the patient will not have enough flexibility to cycle and will simply move the pedal backward and forward through a partial revolution. Flexibility will improve until a sufficient range of motion allows cycling. The stationary bicycle will allow the patient to do low intensity work for prolonged periods and therefore improve muscular endurance fitness of the leg.

\section{Exercises}

- S.L.R. with weight/s on the foot.

- Knee flexion exercises. Started with a pillow under the knee and progress by lowering the manually supported leg. while the thigh is fully supported on a chair or plinth.

- One-legged cycling (I5 - 20 mins.), progressing to using two legs $(30-40$ mins. $)$.

- Isokinetic exercises.

- Functional cxercises. Start with walking and later include walking on inclines, balance board training. stop-start jogging and figure-of- 8 running. Special attention must be given to the activities which the person will later be required to perform during sport or functional activity. Functional demands will differ between individuals.

\section{Return to sport}

The patient should undergo a vigorous fimess test before he may return to competitive sport. The test should include the type of exercise and physical stresses that are likely to be placed on the knee during the particular sport in which the patient wishes to compete. If the patient has pain and/or swelling in or around the knee following the test, he is not ready to return to competitive sport and must undergo further rehabilitation before being re-tested.

\section{CONCLUSION}

Knee meniscectomy is one of the most commonly performed operations. There has been a general lack of awareness of the need for rehabilitation with regard to endurance and strength training at a full range of angular velocities of knee movement. There is a need for rehabilitation centres which have adequate facilities which includes isokinetic exercising equipment.

The physiotherapist conducting the rehabilitation programme must have a good knowledge of the sport or activities that the patient will be required to perform following his return to normal activities. This ensures that the patient is trained and later tested in the specific activities he will later be performing. This may help to prevent re-injury to the leg.

\section{References}

Campbell, D. E. and Glenn W. (1979). Foot pounds of torque of the normal knee and the rehabilitated post-meniscectomy knee. Phys. Ther., 59, 418-421

Clarkson, P. M., Johnson, J.. Dextrateur, D., Leszeznski, W., Wai, J. and Melchionda, A. (1982). The relationship a mong isokinetic endurance initial strength level and fibre type. Res. Q. Exerc. Spor\%, 53, 15-19.

Costill, D. L.. Fink. W. J. and Habinsky, A. J. (1977). Muscle rehabilitation after knee surgery. Physician Spor/s Med., 5, 71-74.

Costill, D. L., Coyle, E. F.. Fink, W. J., Lesmes, G. R. and Witzman, F. A. (1979). Adaptations in skelet al muscle following strength training. J.A.P., 46, 96-99.

Coyle, E. F.. Costill. D. L. and Lesmes, G. R. (1979). Leg extension power and muscle fibre composition. Med. Sci. Sports, 2, 12-15.

Coyle. E. F., Feiring, D. C., Rotkis, T. C., Cote I11, R. W., Roby. F. B., Lee, W. and Wilmore, J. H. (1981). Specificity of power improvements through slow and fast isokinetic training. J.A.P., 5I, 1437-1442.

Dutchic. J. J. R. and McLoed. J. G. (1943). Rehabilitation after meniscectomy. Lancet, I, 197-199.

Eriksson, E. (198I). Rehabilitation of muscle function after sport injury. A major problem in sports medicine. Int. $J$. Sports Mcd., 2, 1-6.

Fox, E. L. and Mathews. D. K. (1981). The physiological basis of physical education and athletics. Saunders College Publishing. Philadelphia. 101-102; 140-141.

Grimby. G. (1982). Isokinetic training. Int. J. Sports Med., 3, $61-64$

Gough. J. V. (1975). Post-operative management of meniscectomy patients. Physiother., 61, 109-110.

Gough, J. V. and Ladley. G. (1971). An investigation into the effectiveness of va rious forms of quadriceps exe rcises. Physiother., 57, 356-361

Gowitzke, B. A. and Milner, M. (1980). Understanding the scicntific basis of human movement. 2nd ed. Williams and Wilkins, Baltimore. p. 141

Krackow, K. A. and Vetter, W. L. (1981). Knee motion in a long leg cast. Am. J. Sports Med., 9, 233-239.

Lantzounis, L. A. (1931). Derangement of the menisci of the knce joint. Surg. Gynec. Obstet., 53, 182-188.

Lconard. M. A. (1975). An evaluation of two post-meniscectomy regimes. Physiother., 60, 110-111.

Luck, J. V., Smith, H. M. A., Lacy, H. B. and Shands, A. R. (1948). Orthopedic survey in the army air forces during World War 11. Introduction to internal derangements of the knee. Arch. Surg., 57, 642-674.

McAustland, R. W. (1943). A study of derangement of semilunar cartilages based on 850 cases. Surg. Gynec. Obster., $77,141-152$.

McDonough, A. L. (1981). Effects of immobilization and exercise on articular cartilage. A review of literature. $J$. Ortho. Sports Phys. Ther., 13, 2-5.

McArdle, W. D.. Katch. F. 1. and Katch, V. L. (1981). Exercise physiology. Lea and Febinger. Philadelphia. p. 175.

Mcekison. D. M. (1944). The operative treat ment of injuries to the semilunar cartilages in personnel of the British Air Force. Can Med. Assoc. J., 51, 517-520.

Nelson, M. A. (1968). Early a mbulation following meniscectomy. Ann. Phys. Med., 9, 282-287.

Rosborough, D. (1970). A comparison of two methods of post-operative management of patients following meniscectomy. J. Bone Joint Surg., 52(B), 1, 177.

Shernan, W. M., Pearson, D. R., Plyley, M. J.. Costill, D. L.. Habansky, A. J. and Vogelsang, D. A. (1982). Isokinetic rehabilitation after surgery. Am. J. Sports Med., 10, 155161.

Smillie, I. S. (1949). The quadriceps in relation to recovery from injuries to the knee joint. Physiorher., 35, 51-57.

Smith, M. J. and Meiton, P. (1981). Isokinetic versus isotonic variable training. Am. J. Sports Med., 9, $275-$ 279. 
Terhurne, S. R., Eddleman. T. S., Thompson. S. B. and Read. B. S. (1943). The care of the knee following excision of the meniscus. I. Bone Jom Surg. 15, 663-669.

Weingarden. S. I.. Louis, D. L. and Wavlonis, G. W. (1979). Electromyographic changes in post-mcniscectomy patients. JAMA. 241, 1248-1250.

Westers, B. M. (1982). Factors influencing strength testing and exercise prescription. Physiolher., 68, 42-44.

Wyatt. M. P. and Edwards, A. M. (1981). Comparison of quadriceps and hamstring torque values during exercise. $J$. Orho. Sports Phys. Ther., 3, 48-56.

Wynn-Parry, C. B., Nichols, P. J. R. and Lewis, M. R. (1958). Menisccetomy. A review of 1723 cases. Ann. Phys. Med., 4, 201-215.

Yocum, L. A., Baclaman. D. C., Noble-Bates, H. and Hoover, R. L. (1978). The deranged knee. Restoration of function. Am. J. Sporis Med., 6, 51-53. 